\title{
PSICOLOGIA, RELIGIÃO E ESPIRITUALIDADE
}

DOI: 10.22289/2446-922X.V5S1A2

\author{
Alice Ribeiro Soares Costa ${ }^{1}$ \\ Roseline Martins Sabião \\ Guilherme Bessa Pereira Ferreira
}

FREITAS, M. H., ZANETI, N. B., \& PEREIRA, S. H. (2016). PSICOLOGIA, RELIGIÃO E ESPIRITUALIDADE (1A ED., VOL. 1). CURITIBA, PR: JURUÁ.

O livro 'Psicologia, Religião e Espiritualidade' reúne 10 artigos organizados por Freitas, Zaneti e Pereira, cujo objetivo é refletir acerca das possibilidades de articulação entre esses temas, visando ampliar as perspectivas que se tem sobre o campo.

O primeiro capítulo nomeado ‘A Produção Científica Atual (2008-2014) em Psicologia da Religião e da Espiritualidade no Brasil', escrito por Marques e Rigo, apresenta uma pesquisa que resgata a trajetória de estabelecimento e reconhecimento da área de estudo que relaciona os temas de psicologia, de religião e de espiritualidade, chamada de Psicologia da Religião e da Espiritualidade (PRE). As autoras apresentam a revisão a partir de onze categorias temáticas, que são: Politica, Contemporaneidade e Evolucionismo, Psicologia Social da Religião, Pastoral e Historias de Vida e Religião, Mundo do Trabalho, Simbolismo Católico, Experiências Religiosas e Profissionais de Saúde, Experiências Anômalas e Identidade, Personalidade, Atendimento em Saúde e Qualidade de Vida, Adolescentes, Idosos e Saúde Geral, Religiões Afro-brasileiras, Saúde Mental e Clinica Psicológica, Escala de Mensuração, Psicologia da Religião e Estudantes de Psicologia e Interpretação Psicanalítica do Fenômeno Religioso.

Essas categorias mostram como PRE esta interligada às mais diversas temáticas o que faz dela uma área de difícil delimitação. Os estudos registraram a existência de instrumentos de pesquisas validados referentes à PRE, mostrando que se trata de uma área em ascensão e ampliação. Indicaram também as perspectivas futuras da PRE, têm apontado para: aproximação com a Psicologia Anomalística; crescente interesse em estudar as experiências religiosas e espirituais correlacionadas à fase do desenvolvimento, em especial a adolescência e a terceira idade; as relações da Religião e Espiritualidade com a saúde; olhares voltados pra multirreligiosidade no contexto brasileiro e novas perspectivas na área da psicoterapia que

\footnotetext{
${ }^{1}$ Endereço eletrônico de contato: alicefaculcp@gmail.com

Recebido em 18/09/2018. Aprovado pelo conselho editorial para publicação em 01/11/2018.
}

Julho, 2019; Vol. X(Sup/1):43-51. 


\section{IIII Fórum de Debates Psicologia na Contemporaneïdade}

possibilite técnicas e praticas pra lidar com religião e espiritualidade no contexto de atendimento psicoterápico. Remetendo à dimensão espiritual humana, indo além da definição biopsicossocial.

O segundo capítulo 'Concorrências entre a Psicologia e a religião' escrito por Ênio Pinto, descreve as relações possíveis entre psicologia e religião. Inicialmente se debruça sobre a reflexão dos vários significados da palavra 'concorrer' registradas no Dicionário Houaiss da Língua Portuguesa, e encontra seis princípios fundamentais sobre os quais discorre no decorrer do capítulo, sendo estes: a confluência, a disputa, a coexistência, o mesmo nível, a contribuição e a concordância.

O autor ao abordar as acepções do verbo concorrer conclui mostrando que a confluência pode ser saudável ou patológica e é a laicidade que permitira o equilíbrio entre as duas. Já a disputa é o terreno mais visível e que traz intensas restrições, criticas e tentativas de prevalência, sendo estas, no campo religioso vistas com a ideia de que à fé cura e a terapia poderia diminuir ou perder a crença em Deus. E no que tange a psicologia, esta diz que a religião solapa a autonomia e a liberdade, alienando as pessoas. Na coexistência o autor trás a necessidade de se ampliar a compreensão do papel e o espaço que a psicologia e a religião exercem no cotidiano, no qual a cooperação entre elas abre possibilidades de autoatualização e de ajustamento criativos para o desenvolvimento da espiritualidade. Um exemplo é o manejo e a compreensão do enfrentamento religioso (coping) como um fator importante na busca e na manutenção da saúde existencial.

No sentido do mesmo nível, o autor trás duas dimensões entre psicologia e religião. A primeira é a tentativa da psicologia de alcance populacional, no que diz respeito à psicoterapia, que acaba não sendo pra todos, embora na teoria pudesse ser, já religião seja qual for predomina sobre todos os países, na segunda a psicologia pode se igualar à religião através da profundidade e da densidade de vivências intimas pelo convite ao mergulho no mais profundo da complexidade humana, a caminhada infindável em busca de autoconhecimento e da confecção de sentidos existências. No aspecto da concorrência como contribuição, a psicologia pode contribuir com a religião no processo da formação e no cuidado psicológico de líderes religiosos, como acontece em diversos seminários no Brasil e em outros países ocidentais.

Outra contribuição importante é que a psicologia mostra as mudanças que a religião pode sofrer ao longo do tempo, por mais institucionalizada que ela seja. Já a principal maneira da religião cooperar com a psicologia é através do dialogo no qual se reconhece que ambas visam um objetivo em comum, a vida humana. E por último a concordância, neste momento a psicologia e a religião coincidem na necessidade de entrega à vida como ato de saúde (para a psicologia) e fé (para a religião). 


\section{IIII Fórum de Debates Psicologia na Contemporaneïdade}

Saúde e fé se concentram em um alicerce básico, a confiança, pois através desta abrese portas para o sentido do dia-dia, para cada fenômeno vivido e para própria vida. Isso inicia com a compreensão de que somos processo, de que somos gerúndios, sempre inacabados e desconhecidos, capazes de nos surpreendermos conosco mesmo em meio a uma aprendizagem constante.

O terceiro capítulo 'Religiosidade e bem-estar psicológico no contexto da clínica psicoterápica: um estudo fenomenológico' escrito por Machado e Holanda, trazem a percepção da carência de posicionamento teórico e metodológico das abordagens psicoterapêuticas e dos terapeutas quanto ao tema religião e religiosidade.

O objetivo foi traçar um panorama sobre a presença da religiosidade no contexto psicoterapêutico e sua relação com o bem-estar psicológico do paciente, compreendendo este cenário a partir do olhar dos profissionais de psicoterapia. Foram realizadas entrevistas semiestruturadas com três psicólogos (P1, P2 e P3) que aderiram à linha fenomenológicaexistencial. Antes de apresentarem os resultados, os autores discutem sobre definições de espiritualidade e de religiosidade.

A espiritualidade está vinculada a valores, significados e fé, não necessariamente a fé religiosa, mas ao sentido na busca de uma conexão transcendental. Já a religiosidade, pode ser vista como uma disposição individual e privada de se relacionar com o mundo transcendente, conectado com uma religião organizada e institucionalizada que envolve práticas ritualísticas e simbólicas, sendo também uma manifestação da espiritualidade.

Os autores argumentam que a Organização Mundial de Saúde (OMS), através da resolução da $101^{\circ}$ sessão da Assembleia Mundial de Saúde, alterou o conceito de saúde buscando obter uma compreensão mais dinâmica de bem-estar, reconhecendo a importância de fatores mentais, sociais e espirituais nessa questão. Assim apresentam o conceito de 'coping religioso' que visa expressar sobre a relação religião-saúde nos processos psicoterapêuticos. Os autores relatam que, apesar disto, na maioria dos centros de ensino de Psicologia no Brasil não oferecem nas ementas formação para os psicólogos lidarem com demanda sobre religião nos atendimentos clínicos.

Em seguida são apresentados os seguintes resultados: P1 se denomina como cristã da Igreja Batista, trata a questão da religião/espiritualidade $(R / E)$ na sua anamnese com seus pacientes, relata que utiliza da logoterapia como abordagem-metodológica onde está permite trabalhar a expressão e manifestação da espiritualidade no contexto terapêutico; P2 declara ser espirita e Gestalt-terapeuta, reconhece que esta questão de R/E é mais forte em pacientes evangélicos e naqueles que tem conhecimento de espiritismo e de budismo e disse que a R/E ajuda muito em momentos de dificuldades e que procura trabalhar a demanda relacionada à $\mathrm{R} / \mathrm{E}$

Julho, 2019; Vol. X(Sup/1):43-51. 


\section{IIII Fórum de Debates Psicologia na Contemporaneildade}

em favor do procedimento terapêutico; P3 é Gestalt-terapeuta, relata que não segue nenhuma religião, todavia diz que é preciso acreditar, ter fé, e destaca a importância da religião pra enfrentar momentos difíceis, pois percebe isso em seus clientes. P3 ressalta que lida com a religiosidade da mesma maneira que trabalha outras questões dentro da psicoterapia.

Dessa forma os autores argumentam que os profissionais da área da psicologia devem debruçar em conhecimentos científicos estudando sobre religiosidade, religião e espiritualidade, além de manter a conduta ética, compreendendo as diversas formas de vivenciar o campo religioso. Por último mostram que psicologia e religião não podem ser mais vistas como campos distantes, mas sim concomitantes.

O quarto capítulo nomeado 'Hipnose, espiritualidade e construção de sentidos subjetivos' escrito por Neubern descreve a relação histórica entre hipnose e espiritualidade trazendo o cenário da hipnose como possível prática pra lidar com demandas clínicas que sejam atravessadas por questões religiosas. $O$ autor relata e analisa dois casos em que a religião e a religiosidade surgiram como parte da questão envolvendo a demanda clínica; o primeiro nomeado de Clara Hernadez, e o segundo de Luiza Rocha.

O autor argumenta a importância da hipnose durante esses processos como forma de mediação, contribuindo com reflexões a partir da subjetividade do sujeito, o que ajudou a compreender intensos conflitos com o intuito de proporcionar um campo de recurso relevante e ampliado. Mostra a hipnose como uma proposta clínica, respaldada em pesquisas científicas, ressalta que a técnica da hipnose não deve ser vista como mero instrumento mecânico, mas pode se tornar um contribuinte para o processo da construção de sentido característico do processo terapêutico.

O quinto capítulo é nomeado como 'Sexualidade, Religiosidade e Espiritualidade na Experiência Feminina' e foi escrito por Zaneti, Freitas, Castro e Almeidas; as autoras investigam as dimensões da sexualidade, da religiosidade e da espiritualidade reconhecendo que essas são experimentadas de maneira fragmentada, especialmente por mulheres que, devido à tradição cultural, são tolhidas no pleno exercício da sexualidade concomitante à pratica religiosa/espiritual. Para exemplificar o quanto essa questão pode ser problemática, citam exemplos de situações clínicas em que a religiosidade e a sexualidade configuram tensões na subjetividade feminina exatamente por serem compreendidas como dimensões contraditórias. As autoras fazem então uma reflexão teórica sobre essas três dimensões buscando apontar para possíveis elaborações de coerência entre elas.

Iniciam com uma reflexão sobre sexualidade, reconhecendo o papel fundamental da psicanálise freudiana na compreensão do tema, abordando as elaborações de Freud, Reich e Jung, apontando as contradições e confluências entre esses autores. Outro pensador que as

Julho, 2019; Vol. X(Sup/1):43-51. 


\section{IIII Fórum de Debates Psicologia na Contemporaneildade}

autoras reconhecem como fundamental no debate é M. Foucault, para quem é necessário pensar sobre o tema a partir da perspectiva cultural e histórica, o que faz saber que a compreensão da sexualidade e - a maneira como ela é experimentada - muda conforme o contexto sociocultural; as autoras adotam esse modo de entender a sexualidade para desenvolver a reflexão que se propõem.

Em seguida, discutem sobre o sentido das palavras espiritualidade, religião e religiosidade, demonstrando que se trata de coisas diferentes: religião diz respeito a questões de ordem social, cultural e institucional; já religiosidade/espiritualidade diz respeito a elementos íntimos, subjetivos e transcendentais. Neste ponto do texto, elaboram sobre como a religião é importante na construção da experiência social, e apontam, a partir de Foucault, que a religião acaba se firmando como uma importante instituição discursiva no sentido de produzir uma disciplina do modo como os sujeitos se relacionam em sociedade.

Por fim argumentam a partir da fenomenologia de Merleau-Ponty como as questões da espiritualidade e da sexualidade não podem ser compreendidas como apartadas uma vez que ambas as experiências se dão no que Merleau-Ponty conceitua como corporeidade. Para as autoras esse reconhecimento é fundamental para uma compreensão e experimentação da espiritualidade, da cultura religiosa e da sexualidade de maneira coadunada e coerente.

O sexto capítulo nomeado como 'Saúde e Espiritualidade: Reflexões a partir do uso Ritualístico da Ayahuasca' escrito por Assis e Conceição aborda a relação entre religião e saúde partindo do estudo do uso ritualístico da ayahuasca, entendendo como fenômeno religioso ligado a saúde. As autoras discutem sobre o que é saúde e cura nos conceitos tradicionais ayahuasqueiros, entendendo que saúde é sempre articulada com as ações cultuais da sociedade e se organiza em três setores: o primeiro é profissional que é o setor institucionalizado pra atender a população, o segundo é o informal que está no campo da família, amigos, o terceiro é a tradicional que não é reconhecida pelo sistema profissional, mais está presente nas crenças culturais difundidas ao longo tempo, como as rezadeiras, parteiras, os raizeiros, os pajés, os xamãs e outros. É este tipo de cuidado e cura que vemos nas tradições ayashuasqueiras.

O uso ritualístico da ayahuasca na sociedade indígena é reconhecido como procedimento de cura de enfermidades, e tem o uso difundido e ampliado a partir de meados do século XX. A cura nesses rituais é vista como um merecimento alcançado a partir da disciplina e aprendizado. $\mathrm{Na}$ atualidade religiões como União do Vegetal, Santo Daime e Barquinha dizem que as enfermidades podem estar interligadas ao espiritual e a ayahuasca age como terapêutica. As autoras ressaltam algumas produções cientificas da ayahuasca com relação à saúde e mencionam que nos últimos seis anos as produções circularam em torno de pesquisas biomédicas, as possibilidades terapêuticas da ayahuasca com interesse especial para o uso da

Julho, 2019; Vol. X(Sup/1):43-51. 


\section{IIII Fórum de Debates Psicologia na Contemporaneïdade}

bebida em sintomatologias relacionadas ao uso de substâncias e depressão, além de outros estudos qualitativos. Desta forma as autoras buscam discutir se a intersecção entre o religioso e o científico nos estudos relacionados à ayahuasca. Mencionam as seguintes conclusões: $O$ Conselho Nacional de Politicas Publicas sobre Álcool e outras Drogas (CONAD) não reconhece o uso ritual da bebida como processo terapêutico, mesmo havendo pesquisas que apontam o uso ritualístico como terapêutico. As autoras apontam para a importância de pesquisas que comprovem e expliquem os efeitos terapêuticos da bebida legitimando o uso dela para esse fim. Com isso, reconhecem que poderíamos vislumbrar uma aproximação efetiva entre os campos da ciência e da espiritualidade.

O sétimo capítulo nomeado 'A identidade dos pretos-velhos na Umbanda carioca: Um ensaio sobre o imaginário social' é escrito por Pereira. Sendo um trabalho de cunho exploratório, que contou com o apoio de três casas de umbanda cariocas onde foram realizadas dez entrevistas semiestruturadas além do método de observação participante, com o objetivo de compreender a cultura religiosa na umbanda e esclarecer o impacto das tradições religiosas no bem-estar subjetivo.

O autor inicia com o esclarecendo o posicionamento da psicologia cultural que vê o homem como produto e produtor de sua realidade e define o terno religião como um artefato poderoso, capaz de estabelecer uma força estruturante no tecido social. Para a compreensão do objeto de estudo o autor faz referência às contribuições de Donald Woods Winnicott, e inicia descrevendo sobre 'fator cuidado' como base da existência humana presente desde os primeiros cuidados dados ao bebê. Em seguida define processo de maturação e o ambiente facilitador, sendo que o ambiente facilitador é onde o sujeito cresce com o intuito de estabelecer o self autônomo, tendo assim um desenvolvimento saudável, que está relacionado à exploração criativa do sujeito.

Essa criatividade dá sentido a vida e faz com que o mesmo se sinta real, possibilitando o processo de maturação. Em seguida, é apresentada uma breve narrativa do contexto histórico da umbanda bem como os principais valores dessa religião que congrega tanto a tradição afrodescendente rememorando e celebrando as raízes africanas quando dialoga com o contexto atual de vivência e enfrentamento das desigualdades sociais.

Segundo o autor, a Umbanda é cheia de processos simbólicos que visam o empoderamento tanto dos sujeitos que dela participam quanto da própria dogmática ritualística. Assim, a tradição umbandista acaba oferecendo uma forma de organização e apoio mútuo especialmente para afrodescendentes e mestiços. Desse modo, a característica marcante desta religião torna-se o suporte que os participantes oferecem uns para os outros bem como as orientações e ensinamentos dos pretos-velhos.

Julho, 2019; Vol. X(Sup/1):43-51. 


\section{Fórum de Debates Psicologia na Contemporaneídade}

O autor relaciona esse tipo de relação de cuidado e proteção à relação mãe-bebê estudada por Winnicott, isso porque no cerne da religião umbandista está o desenvolvimento de laços relacionais que rememoram os familiares. O autor conclui que os sentimentos de cuidado provindos desta relação se tornam suporte social que centraliza os vínculos que contribui para o equilíbrio da integridade física e psicológica do individuo.

O oitavo capítulo nomeado ‘Escalas de Orientações Religiosas Intrínseca, Extrínseca e de Busca para o emprego na pesquisa com idosos' escrito por Silva, Fukuda, Freitas e Alves, recordam que a expectativa de vida dos brasileiros está crescendo e que o Brasil é um país considerado religioso, mostrando a importância de estudar gerontologia e religiosidade.

Os autores debatem a importância do sentimento religioso a partir de Allport para quem este sentimento pode ser uma solução compreensiva para as demandas da vida desde que usado de modo racional. Assim, definem duas perspectivas de sentimento religioso, a intrínseca, que é quando o individuo não vê a religiosidade como objeto, mas como valor interno, e a extrínseca que pode ser vivida de duas formas, a primeira como conforto pessoal e a segunda para ganhos sociais. Para este estudo os autores contaram com 478 idosos na escala psicrométrica (EOR) e cinco idosos na analise semânticas (EB), sendo esta escala denominada como Quest Religion, que é composta por dois itens: a Escala de Orientação Religiosa Intrínseca e Extrínseca (EOR) e Escala de Religiosidade de Busca (EB).

Os resultados mostraram à abrangente da influência cultural, pois foi o primeiro fator encontrado nas duas escalas que mais evidencia aspecto forte que conecta a vivência de religiosidade intrínseca. Outro aspecto que merece destaque veio da escala de 'Religiosidade de Busca' que está voltada para compreender o amadurecimento dos idosos em questionar ou aceitar fatos da vida. Os resultados mostraram que dentre esse grupo tanto os religiosos quanto os não religiosos demonstram maior capacidade de aceitação, isso faz com que os autores levantem a hipótese de que isso se deve ao amadurecimento característico das pessoas dessa faixa etária.

O nono capítulo nomeado 'Orientação Religiosa e Saúde Mental em Adolescentes no Brasil, na Suíça e na Alemanha' escrito por Hoffmann e Kappler, argumentam que dentre as várias fases do ciclo da vida a adolescência é considerada um momento crucial, pois costuma ser o período de enraizamento de valores que serão norteadores da vida adulta, bem como um período de descobertas e mudanças profundas. Desse modo, valores e crenças religiosas podem influenciar fundamentalmente a maneira como essa fase é vivida.

Os autores mencionam várias pesquisas da fase infantil e adulta com relação à religiosidade, mas ressaltam os poucos trabalhos voltados para adolescência. Propõem então a uma investigação que conflua religião, saúde mental e desenvolvimento de identidade na fase

Julho, 2019; Vol. X(Sup/1):43-51. 


\section{IIII Fórum de Debates Psicologia na Contemporaneïdade}

da adolescência. Para isso foi aplicado o questionário Valeues und Religious Orientations in relation to identity Development na mental Health-Adolescents' Perspective (VROID-MHAP) em adolescentes brasileiros e posteriormente faz-se a comparação dos resultados com os encontrados na Alemanha e Suíça.

A pesquisa contou com 750 adolescente do estado de Brasília e incluiu recorte de classes. O estudo proporcionou os seguintes resultados: a maioria dos jovens que participaram das pesquisas nos três países pertence a alguma religião, mas o Brasil o número de adeptos é maior quando comparado com Alemanha e Suíça. Segundo os dados da escala, os jovens brasileiros demonstram maior sentimento religioso ou religiosidade quando comparados com os jovens alemães e suíços. Isso vale tanto para aqueles que se descreveram como adeptos a uma religião quando os que se disseram não adeptos.

No que se referem à saúde mental os jovens brasileiros apresentaram mais sintomas de sofrimento emocional e hiperatividade que em relação aos da Alemanha e da Suíça. Consta também uma diferença nas relações interpessoais com colegas, onde os brasileiros demonstram menos dificuldade na interação social que os alemães e os suíços. A partir desses dados os autores consideraram difícil estabelecer uma relação de interdependência positiva entre a religiosidade e a saúde mental e julgaram que isso se dá devido à complexidade das vicissitudes subjetivas.

O décimo e último capítulo nomeado 'Religiosidade e Bem-Estar Subjetivos em Estudantes Portugueses e Brasileiros' é escrito por Ferreira, Pinto e Neto. Os autores pesquisam a forma como os sujeitos internalizam a religiosidade e como ela influencia a satisfação com a vida e a afetividade de jovens universitários portugueses e brasileiros. Este trabalho contou com a participação de 352 jovens estudantes do ensino superior, são 176 jovens de cada país, onde 91,8 \% diz ser católico. Foram utilizadas duas escalas: a primeira - Escala de Atitude face ao cristianismo e a segunda- Escala do bem-estar espiritual.

Os autores discutem sobre religiosidade e bem-estar subjetivo e tem como foco principal responder a três perguntas: 1) Até que ponto o gênero influencia a religiosidade? ,2) Até que ponto a cultura influencia a religiosidade? 3) Que relações existem entre religiosidade e bemestar subjetivo? Sendo assim, este estudo levantou os seguintes resultados: a análise de gênero não influência na religiosidade e no bem-estar dos jovens universitários tanto portugueses como brasileiros, a frequência nas instituições religiosas influenciam a religiosidade e o bem-estar existencial dos jovens, porém não há diferença significativa entre o prazer de viver a vida e nem nos afetos positivos e negativos entre jovens que manifestam alguma religiosidade e aqueles que não manifestam.

Julho, 2019; Vol. X(Sup/1):43-51. 


\section{IIII Fórum de Debates Psicologia na Contemporaneïdade}

Os autores ainda fazem uma discussão sobre a diferença entre religião e religiosidade para refletir sobre os dados apurados. Portanto este trabalho permitiu saber o que os jovens sentem e pensam sobre sua existência e a meditar em como a religiosidade interfere na vida do individuo num todo.

Está obra traz diversidade de conteúdo tratando de temas relacionados à Psicologia, Religião e Espiritualidade. Isso é importante, pois mesmo leitores pouco informados sobre a área da PRE, retiram um grande proveito da leitura, que se revelou muito informativa. Para aqueles interessados nas intersecções entre a Psicologia e as religiões o livro trás alguns capítulos que refletem essa relação tanto em termos teóricos quando práticos - especialmente no contexto da clínica. Reconhecendo que a Psicologia é uma disciplina que investiga a subjetividade e que a prática religiosa atravessa os processos subjetivos e sociais, o livro trás pesquisas que mostram o impacto da religiosidade na subjetividade das pessoas, especialmente no tocante saúde mental e bem-estar.

Apesar de muito interessantes, alguns capítulos trouxeram pesquisas parecidas o que deu à leitura um aspecto repetitivo. Além disso, são pouco conclusivos os resultados debatidos que relacionavam a religião com a saúde mental, mostrando, entretanto, que essa relação é mais forte entre religiosidade e bem-estar. Outra questão importante que tornou a leitura desafiadora é a repetição do debate que explica a diferença entre religião, religiosidade e espiritualidade (sendo que a diferença entre esses dois últimos não ficou clara).

Por fim, o livro também careceu de um comentário final, como um posfácio, que ajudasse a coadunar as ideias abordadas relacionando-as a partir das perspectivas fundamentais dos autores/organizadores. Ainda assim o livro contribui para o aprofundamento do interesse em torno da PRE e ajuda a difundir tantos resultados de algumas pesquisas quanto levantar outros questionamentos que inspirariam mais investigações e reflexões.

A presente obra foi desenvolvida na área de Psicologia da Religião e da Espiritualidade em contexto brasileiro, em alguns capítulos nos permite a reflexão intercultural com centros de pesquisas de países europeus, onde nos revela ser essencial dar e conhecer a estudantes, professores e pesquisadores em psicologia e áreas afins o que se tem de mais recentes sobre a temática. É um estudo que permite ampliar o cenário atual da Psicologia da religião e da espiritualidade.

Dessa forma, promove diálogos entre os estudos realizados, estimulando nossa aprendizagem sobre a questão, é um livro para todos que anseiam entender sobre o assunto e orienta aqueles que desejam, so sobretudo efetuar uma psicologia mais abrangente a cerca da religião/espiritualidade.

Julho, 2019; Vol. X(Sup/1):43-51. 